\title{
Drug Policy: Insights from Mathematical Analysis
}

\author{
Jonathan P. Caulkins \\ Carnegie Mellon University \\ H. John Heinz III School of Public Policy and Management \\ 5000 Forbes Ave. \\ Pittsburgh, PA 15213-3890 \\ and \\ RAND Drug Policy Research Center \\ 201 North Craig St. \\ Pittsburgh, PA 15213 \\ caulkins@,cmu.edu
}

\section{Abstract \\ I. Introduction}

Illicit drug use is clearly an important health problem. There are some 600,000 emergency department episodes in the US every year that are related to illicit drugs (SAMHSA, 2002a). National mortality estimates are not available, but there are probably on the order of 20,000 drug-induced deaths a year (SAMHSA, 2002b), with many more indirectly related to drug use. Some 5 million Americans are in need of drug treatment, and less than $40 \%$ get it (Epstein and Gfroerer, 1998; Woodward et al., 1997). Injection drug use is a leading cause of the spread of infectious diseases such as HIV/AIDS and Hepatitis C (CDCP, 2001). The social costs of illicit drug use approach those of alcohol and tobacco (Rice et al., 1990; Bartlett et al., 1994; Harwood et al., 1998). No one has estimated how many quality adjusted life years are lost due to illicit drug use, but the number is no doubt substantial, particularly since those who die from illicit drug use are younger than those who die from most other causes.

Not surprisingly there is an energetic debate concerning how best to control drug use and related consequences, to which Operations Research/Management Science has made important contributions. Nevertheless, drug policy is unlike other health policy domains in important ways, and this article begins with a review of some important differences. The following sections then highlight key insights quantitative models have generated concerning the relative effectiveness of different interventions, including how that effectiveness varies over the course of a drug epidemic.

\section{How is Drug Policy Different?}

Drug policy differs from other health policy domains in a number of respects. For one, we care as much about outcomes for other people as we do about outcomes for the person with the "condition". Cancer generates health consequences for people other than the patient, such as stress and depression among family members. Nevertheless, the focus is clearly and appropriately on the person who has cancer. 
The consequences of drug use are more diffuse. Fear that addicts or addicts' suppliers will hurt non-users is an important source of public concern about drug use. One can argue that such fears are exaggerated, but there are other health consequences for non-users which are under-appreciated. For example, addiction of all kinds, including to illicit drugs, is an important contributor to child abuse and neglect.

In this respect drug policy is more like a public health problem than a medical problem, and the behavioral component invites comparisons to second-hand smoke and drunk driving accidents rather than malaria or cholera. However, drug use is very much a "contagious" phenomenon that can usefully be studied by epidemic models, as will be discussed below. So analyzing drug policy merges important strands from behavioral health and the contagious disease aspects of public health.

Another fundamental difference with drug policy is that the underlying activity is illegal. This has myriad ramifications ranging from making data collection difficult to the fact that law enforcement plays an important role in controlling the prevalence and consequences of this "health problem."

An important consequence of drugs' illegality is the existence of black markets which are the proximate source of many drug-related harms (MacCoun and Reuter, 2001). Obviously the markets would not exist were it not for the drug use, and reducing drug use (e.g., through treatment) shrinks the markets, so a systems analysis should consider market outcomes. The need to do so distinguishes drug policy from other health policy domains. There is no market for heart disease, and with some exceptions, such as so-called "nuisance bars" (Cohen et al., 2002), the markets for tobacco and alcohol are not themselves a major problem.

A subtle consequence of the illegality of drug use is that it encourages the lumping together of all types of use because they are all the same in the eyes of the law. Not only does this blur distinctions between substances with very different health risks (marijuana and heroin are both "Schedule I" drugs), but it also blurs distinctions between dependent and non-dependent use.

Drug dependence is a well-defined medical condition that can be diagnosed and treated. Recreational use by non-dependent persons is not, and more often than not it does not lead to dependent use. Thus the vast majority of people who use an illicit drug never have a drugrelated medical condition (even though they help support a drug market that generates adverse health outcomes for others).

To complicate matters further, many of those with this medical condition deny they have it and/or are ambivalent about getting rid of it. This contributes to very low compliance with treatment. It has become common to point out that compliance rates (e.g., rates of testing negative for drugs) are not so different than rates of compliance with medical regimens for conditions such as hypertension or diabetes (e.g., admonitions to alter one's diet). However, that obscures the fact that few diabetics want to have diabetes whereas quite a few drug users are not sure they want to stop using drugs. Furthermore, many dependent users do not have a health insurance company or personal physician vested in addressing their dependence.

More such differences could be noted, but these suffice to make the basic point that drug policy is a part of health care policy that necessarily must draw its "system boundary" quite broadly. One could examine instead "drug treatment policy," focusing on issues of queue management and matching treatment modalities to patients (e.g., Kaplan and Johri, 2000), but that is a different topic. 


\section{Scope and Methods of Analysis}

A comprehensive discussion of everything within the broader domain of drug policy analysis is not possible in this short space, so this chapter focuses on insights from quantitative analysis of "strategic" drug policy choices. At the highest level, this paradigm thinks of drug policy as a resource allocation problem. Some governmental entity decides how many resources to allocate to drug control and how to divide those resources across broad programmatic areas in order to achieve the greatest impact. Such analysis is helpful because a variety of drug control strategies exist, and the drug "system" is complex, so it is not intuitively obvious what the best combination of strategies is.

Analyses of this sort began to appear in the 1970s in response to the heroin epidemic, (e.g., Schlenger, 1973; Levin et al., 1975; Gardiner \& Schreckengost, 1987), and became more common after the spread of cocaine. Early contributors to this second wave included groups at RAND's Drug Policy Research Center (Crawford et al., 1988; Reuter et al., 1990; Kahan et al., 1992, 1995; Kennedy et al., 1993; Childress 1994a, 1994b; Dombey-Moore et al., 1994; Everingham and Rydell, 1994; Rydell and Everingham, 1994), UCLA (e.g., Hser et al., 1992; Homer, 1993a, 1993b), Carnegie Mellon University's Heinz School (Caulkins and Padman, 1993a, 1993b; Caulkins, 1993a, 1993b; Gorr and Olligschlaeger, 1994; Blumstein and Cork, ), and later the Technical University of Vienna (e.g., Dawid and Feichtinger, 1996; Gragnani et al., 1997; Kort et al., 1998; Dworak, 1999; Feichtinger et al., 2002; Fent et al., 2002) as well as individuals elsewhere (e.g., Baveja et al., 1992, 1997), with growing communities of analysts elsewhere in Europe (e.g., Rossi, 1999, 2001; EMCDDA, 2001) and notably in Australia (Weatherburn and Lind, 1997; Weatherburn et al., 2001; Law et al., 2001; Kaya, 2001). There is also an extensive and fascinating literature on the intersection of injection drug use and HIV/AIDS that, for reasons of space, is dealt with very briefly here. offer an excellent review.

The method employed in this paper is simply to skim insights from this literature that can be communicated effectively without detailed technical exposition of the underlying models and analysis, with some bias toward results that the author has observed to be compelling to policymakers and non-academics.

The methods employed by the underlying literature are diverse, but mainly involve construction of some nonlinear descriptive model of the behavior of drug users and sometimes sellers, with inputs corresponding to various policy alternatives. Depending on the sophistication of the model and associated analysis, the models are then used to reproduce past and present behavior and/or to make recommendations for the future, either in "what if" policy simulation mode or through some formal optimization.

Collectively the greatest weakness of the literature is the inability to truly validate these models given the paucity of reliable data and the inherently small sample size when the unit of analysis is at the national level. A consequence is that specific numerical results are not very precise; the models are more reliable for general structural insights of the sort offered below. The models' greatest contribution stems from precision of a different sort, the precision and rigor that comes from translating less quantitative scholars' mental models into equations, from which powerful insights often emerge from relatively simple analysis. 


\section{Results}

A number of insights emerge directly from models of use, without explicit consideration of specific control measures. We begin with a few such insights before considering results from models of prevention, treatment, enforcement, and drug epidemics.

\section{Models of Use}

Everingham and Rydell (1994) made a pioneering contribution to understanding of drug policy by developing a simple two-state Markov model of cocaine demand that distinguishes between so-called "light" and "heavy" users. Figure 1 illustrates a modified version of the model with flow rates recently updated by Knoll and Zuba (2002).

Figure 1: Everingham and Rydell's (1994) Light and Heavy User Model with Flow Rates Updated by Knoll and Zuba (2002).

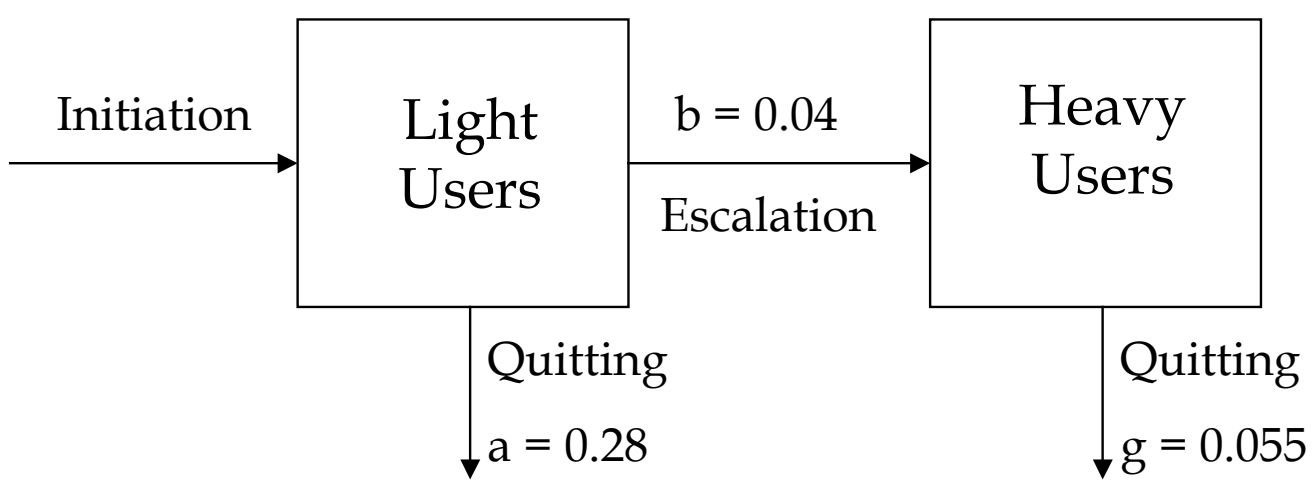

Several insights emerge from this simple model. For example, most (roughly $5 / 6^{\text {th }}$ ) of those who try cocaine do not escalate to heavy use, but those who do persist in the heavy use state for many years $(1 / \mathrm{g}=16$ years $)$. Per capita consumption rates for heavy users are much higher for heavy vs. light users. ${ }^{1}$ As a result, expected lifetime consumption per initiation is on the order of 225 - 475 grams (Caulkins et al., 1999), but that figure is dominated by a very large expected consumption given escalation to heavy use times a small probability of escalating. Given the high social cost per gram consumed, ${ }^{2}$ this implies that the expected social cost per cocaine use career is very large (on the order of $\$ 50,000$ - $\$ 100,000$ per initiate). The median is at least an order of magnitude lower, if not two. Indeed, given that many users appear never to proceed beyond the "very light" stage (Caulkins, 1997), the median cost per cocaine use career could be close to $0 .^{3}$

Highly skewed consumption and social cost distributions are not unique to cocaine. The average marijuana use career involves 375 - 875 grams of consumption, or 1,000-2,000 joints, whereas median lifetime days of marijuana use is less than 100 (Caulkins et al., 2002). For

\footnotetext{
${ }^{1}$ Everingham and Rydell suggested a ratio of 7.25 to 1 . More recently, Abt analysts estimated that "chronic" users spend about 6 times as much per capita as do "occasional" users. (ONDCP, 2001)

${ }^{2}$ Rydell and Everingham (1994) originally estimated social costs of about \$100 per gram, but Caulkins et al. (2002) use newer evidence to develop a figure of \$215 per gram.

${ }^{3}$ Kaya et al.'s (2001) analysis of Australian heroin use data shows that the number of people quitting heroin use over time is highly correlated with the number initiating, presumably because the modal career of use is very short.
} 
heroin in the US, per capita consumption rates are an order of magnitude lower, but the social costs per gram are an order of magnitude higher (Caulkins et al., 2002) and exit rates from dependent use no higher (Anglin et al., 199_), so the expected social cost for someone who escalates to dependent heroin use is at least as high as is the corresponding figure for cocaine. Indeed, inasmuch as light use of heroin is more likely to involve smoking and heavy use to involve injecting, the skew in social cost could be greater. ${ }^{4}$

The sharply different exit rates for light and heavy users (factor of $\mathrm{X}$ difference in Figure 1) and the lag between initiation and escalation to heavy use means that the character of drug use can vary sharply over the course of a drug epidemic, as illustrated in Figure 2 (adapted from Knoll and Zuba, 2002). Demand for cocaine ${ }^{5}$ rose sharply with cocaine initiation did in the mid to late 1970s, but it did not fall when initiation did in the 1980s. Rather, sharp declines in the number of light users were offset by numerically smaller increases in the number of heavy users, whose per capita consumption rates are much higher, leaving overall demand substantially stable for close to two decades. The proportion of that demand attributable to light vs. heavy users changed dramatically, however. In 1980 much of the demand came from light users who are not badly affected by their drug use. By 1990 most of the demand came from heavy users, many of whose lives are dominated by the drug. This picture follows fairly directly from the simple Markov model of use, yet it is so compelling that the Office of National Drug Control Policy incorporated Everingham and Rydell's (1994) earlier version of it in several of its National Drug Strategy Reports (e.g., ONDCP, 1995).

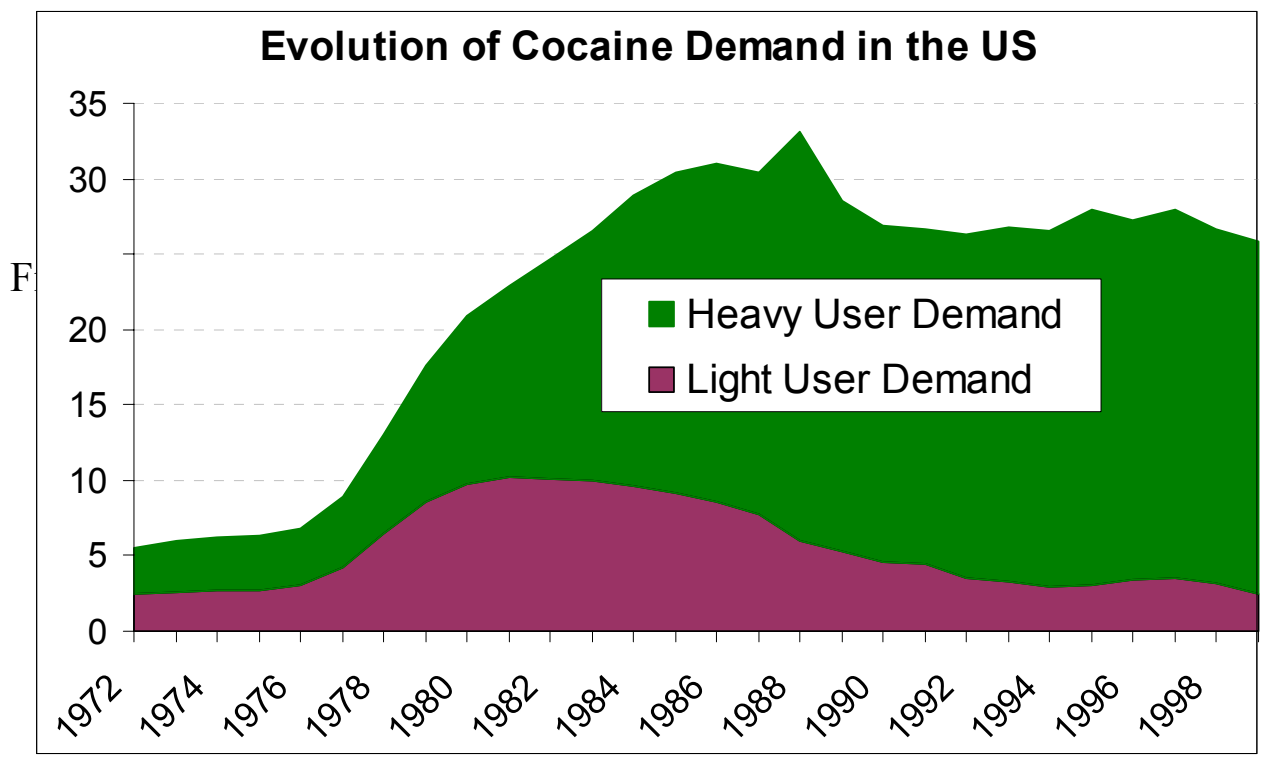

These figures also provide a convenient way of thinking about various drug control interventions. Primary prevention programs seek to reduce initiation. Treatment seeks to increase quitting from heavy use. Enforcement programs seek to do both and also reduce per

\footnotetext{
${ }^{4}$ A tendency for light users to smoke and heavy users to inject heroin would tend to reduce the skew in terms of grams of heroin consumed because injection is the more "efficient" route of administration, although dependent users are also more likely to have developed tolerance and to take larger effective doses.

${ }^{5}$ Demand is proxied by the sum of light and heavy users weighted by their relative propensities to consume.
} 
capita consumption by current users by deterring users and constraining supply. And epidemic models analyze how the relative effectiveness of these interventions varies over the course of drug epidemics such as the one depicted in Figure 2. We turn next to a discussion of key insights relating to these programs.

\section{Reducing Demand Through Prevention}

There has been great confidence that drug prevention is effective and cost-effective. For example, the 1999 national drug strategy (ONDCP, 1999, p.54) stated unequivocally that "The simplest and most cost-effective way to lower the human and societal costs of drug abuse is to prevent it in the first place."

However, there is enormous heterogeneity in programs, ranging from adventure camps to mass media campaigns. Some are more effective than others (Sherman et al., 1997). Likewise, experimental trials have shown some school-based programs to decrease illicit drug use (Ellickson and Bell, 1990; Botvin et al., 1995; Pentz et al., 1998). Yet the most popular schoolbased program, DARE, has not been shown to have any material effect on marijuana use (Tobler, 1997).

Furthermore, the experimental evidence pertains only to self-reported use of indicator substances (e.g., marijuana), through final follow up data collection (typically $9^{\text {th }}$ or $12^{\text {th }}$ grade) by people in the program. However, from a policy perspective one is interested in the impact on actual (not self-reported) use of the more damaging illicit drugs (e.g., cocaine) over the lifetime of all people affected, including those not themselves in the program.

Caulkins et al. $(1999,2002)$ develop mathematical models for projecting total impact from available evidence concerning "best-practice" school-based prevention programs. There is considerable uncertainty concerning the projections, but the bottom line finding is that these programs are cost-effective, but not very effective.

More precisely, drug prevention is not very effective if one thinks it should act like a vaccine that inoculates youth against drug use. If one gives the very best prevention program to a group of youth who would have used drugs, most will go ahead and use drugs anyhow. Even cutting edge school-based programs can only be depended on to reduce marijuana use by $5-15 \%$ and for almost all programs those effects decay by the end of high school. Even recognizing that delayed initiation is associated with lower lifetime use, this translates into reductions in the present value of lifetime consumption in the single digits, and most likely just a few percent, because reductions in lifetime use are only one-fifth to one-third as great as the reductions observed immediately following program completion (Caulkins et al., 2002).

Thus prevention cannot be "the" solution to the drug problem. Indeed, the notion that enforcement merely needs to "hold the line" until prevention can "cut the legs out from under the epidemic" does not seem realistic given that the problem is now more endemic than epidemic. It is similarly unrealistic to hope, as some legalization advocates suggest, that if the money saved by not having to enforce the prohibition were used to fund drug prevention, that could offset any legalization-induced increase in use.

On the other hand, prevention is cheap, even if one recognizes that the dominant true or economic cost of running school-based prevention programs is the opportunity cost of not using class time to teach other academic subjects. The outright budgetary costs for programs delivered by regular teachers who are already on the payroll is tiny. So, since preventing drug use is so valuable and prevention is so inexpensive, prevention is cost-effective even though it is not very effective. 
One "paradox" of prevention that an OR/MS analysis reveals is that only about about onequarter of a prevention program's impact on cocaine use comes from preventing program participants from initiating use. Some comes from reduced use by program participants who do still initiate and use at some level. Still only about one-third of the reduction in consumption is in the form of reduced consumption by program participants. Two-fifths comes from positive spillover to friends and associates of those in the program, and one-fifth comes about because reduced use by all these people shrinks the market, making enforcement against those who remain in the market more effective. Thus conventional evaluations of prevention miss some two-thirds to three-quarters of the effects that would be assessed by a systems analysis.

Another interesting insight is that "school-based prevention should be done fifteen years before one knows we need to do prevention." (Caulkins, et al., 1999) The average age of initiation of "hard" drugs is about eight years after the age targeted by school-based prevention programs. National recognition of a drug epidemic may occur five or more years after the peak in initiation. (US cocaine initiation peaked in 1979; it was recognized as a national crisis around 1984.). Since it takes time to appropriate funds, adapt and scale up prevention programs, etc., this implies that school-based prevention must be started about fifteen years before it is widely appreciated that prevention is needed! Given the contagious nature of drug epidemics, prevention programs that lead an epidemic are likely to be many times more effective than programs run after the epidemic has matured. ${ }^{6}$ Since ability to forecast drug trends is exceedingly limited, the practical implication is that prevention programs should be funded on an on-going basis, not in response to current crises. That is, decisions about prevention should not be made only with an eye toward ameliorating the current epidemic. Instead, prevention should be seen as "lending a hand" with the current drug epidemic and possibly other undesirable social trends, while also serving as a form of "cheap insurance" against possible future epidemics.

Likewise, drug prevention should be - and usually is - generic, not drug-specific. Indeed, less than half of the social benefits of school-based drug prevention stem from reduced use of illicit drugs. The majority stems from reduced smoking and heavy drinking (Caulkins et al., 2002).

\section{Reducing Demand Through Treatment}

Treatment is the most thoroughly evaluated drug control intervention. Indeed, the literature is so large there is even a bibliography just of other literature reviews of drug abuse treatment effectiveness (Prendergast et al., 1998). Most observers conclude that it is costeffective (e.g., Rydell and Everingham, 1994; Gerstein et al., 1994). The Institute of Medicine (IOM, 1996, p.192) summarized the literature by saying "Research has shown that drug abuse treatment is both effective and cost-effective in reducing not only drug consumption but also the associated health and social consequences." On the other hand, a National Research Council Report (Manski et al., 1999) subsequently attacked the evidence base concerning treatment as vulnerable to various methodological biases, concluding that "There is little firm basis for estimating the benefit-cost ratio or relative cost-effectiveness of treatment." The principal complaint was that few true randomized controlled trials had been conducted.

\footnotetext{
${ }^{6}$ Precise statements are difficult because effectiveness ratios are sensitive to the number of heavy users at the beginning of the epidemic, a parameter for which data are particularly weak. See Winkler et al. (forthcoming) for more on how the relative effectiveness of different types of drug prevention varies over the course of an epidemic.
} 
What is clear to a systems analyst, though not necessarily a social scientist, is that decision relevant insight can be gleaned even if it is not possible to produce a bottom line benefit cost ratio. For example, one can work backwards to ask how effective treatment must be to be cost-justified. If the resulting breakeven effectiveness seems implausibly high, one would be skeptical that treatment is a good investment. If it seemed attainable, one might be more optimistic.

Rydell and Everingham (1994) in fact performed such exercises. One of their striking findings was that even if every treatment client relapsed immediately after completing treatment, treatment could still be cost-effective! The full model is too involved to explain here. It tracks cocaine as it is produced and passed through multiple distribution layers and explicitly models user flows, prices, and market dynamics over a 15-year planning horizon. But back of the envelope calculations are sufficient to convey the basic insight.

In terms of the drug use model above, treatment can be thought of as doing three things: it can suppress use while the person is in treatment, it can reduce use between exit from treatment and relapse, and occasionally it may encourage some users to quit permanently. Rydell and Everingham's startling insight is that the first mechanism alone can be enough to make treatment a good investment.

Rydell and Everingham (1994) estimated that the average admission to treatment costs about $\$ 2,000$, the average time in treatment is 3 months, and use is suppressed by about $80 \%$ during treatment. If heavy users consume at a rate of 120 grams per year, the average admission averts about $120 *(3 / 12) * 0.8=24$ grams of consumption through this "incapacitation" effect alone. Since the average social cost per gram is about $\$ 215$ (Caulkins et al., 2002), the social benefit $(\sim 5,000)$ exceeds the cost. ${ }^{7}$ Indeed, the benefit-cost ratio would be greater than one even if every user relapsed immediately after leaving treatment and treatment only suppressed use by one-third during treatment $(120 *(3 / 12) *(1 / 3) * \$ 215>\$ 2,000)$.

One can do a similar breakeven calculation with respect to treatment's impact on exit rates. Suppose the present value of the residual career length of the average treatment entrant were 8 years. (In a Markov model the total residual career length would be $1 / \mathrm{g}=$ , but one should discount back to the present and truncate to recognize that people - especially chronic drug users - do not live forever.)

If the social cost per year of use is approximately 120 grams/year times $\$ 215 /$ grams $=$ $\$ 25,000$ per year, then the discounted social value of getting a heavy use to quit is about $\$ 200,000$. Hence, if even $1 \%$ of treatment admissions led to permanent cessation, the present value of treatment's benefits would equal its costs.

Similarly, if one in twelve people entering treatment cease use for a year (and no one quits permanently and no one else reduces use during treatment) the benefits would exceed the costs. Any linear combination of these three effects would also breakeven. E.g., if one in twenty did not relapse for a year and one in 250 quit, treatment's benefits would exceed its costs even if it had no impact whatsoever on $95 \%$ of clients. In this light,

Pollack (2002) has taken this insight a step further, noting that methadone maintenance (a treatment for heroin users, who often use by injection) can have benefits that can exceed its costs

\footnotetext{
${ }^{7}$ Of course the social cost per gram of consumption averted by treatment could in theory be below average, but more likely it is higher. The biggest danger from light use of cocaine is the possibility of escalation to dependent use, and since many of those in treatment are "referred" by the criminal justice system, consequences of their use may be costly even relative to those of other heavy users.
} 
even if it has no impact on drug use whatsoever - simply because it can reduce the rate at which users spread HIV by sharing syringes.

More generally, interventions can reduce drug-related harm and have positive social benefit cost ratios even if they do not reduce drug use. Indeed, treatment is sometimes described as a "hook" for getting needy people in contact with health and social service agencies. Such a "harm reduction" approach to drug control is common outside the US (MacCoun et al., 1996), although it has not in general been the subject of much formal systems analysis.

As Manski et al. (2001) argue, in the absence of rigorous randomized controlled trials it is not possible to conclude with certainty that treatment is cost-effective, but what is clear from Rydell and Everingham and other's work is that the breakeven points are not very high and that relapse rates are not an adequate metric for evaluating treatment's value. Hence, complaints that "When complete and permanent abstinence is used as a criterion of success, between 60 and 90 percent of clients relapse to drug use within 12 months of treatment" (Manski, et al., 2001, p.243) do not seem damning.

At the same time, Rydell and Everingham provide a cautionary note. If most people relapse, then unless those individuals can be re-enrolled rapidly, there is a limit to how quickly treatment can ameliorate the drug problem. In Rydell and Everingham's model (which assumed that $13.2 \%$ of treatment entrants left heavy use because of that treatment, with two-thirds merely de-escalating to light use), even if every heavy cocaine user received treatment once a year, cocaine use would still only be cut in half over 15 years. Furthermore, Rydell and Everingham did not consider the possibility that such an expansion in treatment might have an adverse feedback effect on initiation, as do Behrens et al. (2000, 2001). Highly imperfect treatment programs, no matter how cost-effective, cannot quickly eliminate an endemic drug problem. Everingham and Rydell (1994) and Caulkins et al. (1999) make similar points concerning prevention.

\section{Supply Side Interventions}

Interventions can affect supply in two ways. Unanticipated interventions can disrupt the market equilibrium. Ideally the disruption takes the form of physical shortage, and the market does not regenerate, but that is not the norm. Usually suppliers adapt, although prices may spike and use decline in the interim (Reuter, 1988). At one time or another over the last 30 years, four different regions have been the principal supplier of heroin to the US (Mexico, South America, Southwest Asia, and Southeast Asia). Similarly, Colombia quickly replaced Mexico as the principal supplier of marijuana to the US in response to paraquat spraying and fears of adverse health-effects of using sprayed marijuana (Kleiman, 1992).

Enforcement can also affect supply even if the intervention is fully anticipated. For example, if smugglers knew that one-quarter of all shipments would be seized, they would ship more than if they thought none would be seized. Indeed one of the early lessons drug policy analysis gave policy makers was that quantity seized is not a direct measure of enforcement's impact on consumption (Reuter, 1988). However, presumably the smugglers would charge more per kilogram landed to make up for their losses. The higher prices represent a shift in supply that affects retail prices and, hence, consumption.

At one time demand was thought to be insensitive to price, but the price elasticity of demand for illicit drugs turns out to be rather high, much higher than for cigarettes. For a review of the literature, see Chaloupka and Pacula, 2000.) Nor does this price-responsiveness seem to be confined to light use reported in surveys. Crane et al. (1997) estimate that the elasticity of 
cocaine emergency department mentions with respect to price is -0.63 , and Caulkins (2001) notes that a simple constant elasticity model predicts emergency department mentions for both cocaine (elasticity -1.3 ) and heroin (elasticity -0.8 ).

These disequilibrium and equilibrium aspects of enforcement's effect on supply are quite distinct, and great confusion can arise if one tries to compare analyses or conclusions concerning one with those concerning another.

Supply-side interventions are most likely to have disequilibrium effects if they quickly affect a large proportion of supply. For most drugs, the industry within US borders is populated by many vertically disaggregated "firms," so it is difficult for enforcement to remove a large proportion of the national domestic distribution network's capacity at any one time (Reuter, 1983). Furthermore, the network is robust because of its many lateral linkages, independent paths, and ability to expand quickly the capacity of individual arcs (Caulkins, 1997b).

There can be greater potential for market disruption with interventions in source countries because there is greater market concentration there. Perhaps the greatest success was when the combination of the Turkish Opium ban, the breaking of the "French Connection" case, and Mexican opium eradication substantially drove up purity-adjusted heroin prices during the mid to late 1970's, before Asian heroin filled the gap. (Reuter, 1985) The greatest success with cocaine was the result of a combination of US efforts and the "war" between the Colombian government and the Medellin-based traffickers in 1989 which led to a sharp (50-100\% at its peak) but short-lived (about 18 months) increase in cocaine prices (Caulkins, 1994). Also, in 1995 Peruvian interdiction of the "air bridge" to Colombia led to a smaller but identifiable increase in cocaine prices (Crane et al., 1997).

There is good reason to believe that transient price increases can have meaningful effects. The heroin scarcity in the 1970s is coincided with the ebbing of the heroin epidemic (DuPont and Greene, 1973). Emergency room and medical examiner mentions declined in parallel with higher cocaine prices in 1989-1990 (ONDCP, 1992), and there was a one-period decline in emergency mentions in late 1995 (SAMHSA, 1998). On the other hand, market disruptions may increase harms (Maher and Dixon, 1999, 2001).

Unfortunately, there are only a few analyses of short-term disruptions (e.g., Crane et al., 1997; Weatherburn, 2002), and essentially no serious estimates of how much it costs to generate disruptions and, hence, few real cost-effectiveness insights.

There have been far more studies of how enforcement might affect the long-run market equilibrium via so-called "risks and prices" calculations of the sort pioneered by Reuter and Kleiman (1986). The "risks and prices" paradigm recognizes that increasing enforcement risks for dealers raises their cost of doing business. Dealers could simply absorb those costs, but presumably prefer to pass them along to users in the form of higher retail prices, which in turn reduce consumption (Caulkins and Reuter, 1998).

The literature on risks and prices calculations generates a number of insights. For example, enforcement is more efficient at seizing drugs in source countries and while being smuggled into the US than it is within the US (more kilograms seized per million taxpayer dollars spent on enforcement). However, the suppliers can also replace the seized drugs more cheaply at these levels. Indeed, the effective cost to suppliers of replacing the drugs seized per million taxpayer dollars spent is lower, not higher, outside the US. Replacing seized drug is just one of component of the "tax" enforcement imposes on equilibrium operations. E.g., Rydell and Everingham (1994) also consider seizure of assets, arrest, imprisonment, incarceration of sellers 
who are also users, and indirect effects on production costs, but they find that the basic pattern persists.

Hence, the only way international operations can be a more cost-effective way to "tax" suppliers is if the tax is "multiplied" as the drugs move down the distribution chain. Boyum (1992) and Caulkins (1990) suggest reasons why there might be such multiplicative price transmission, and Caulkins (1994) finds some evidence for this proposition, but DeSimone (in submission) argues that the additive model is much more consistent with the empirical evidence. Hence, it may be easier to create transitory disruptions through international operations, but unless such a multiplicative price transmission model holds, it is harder for them to drive up equilibrium prices (Reuter, 1985).

Within US borders, the risks and prices model has something of the feel of an arm's race. If enforcement can impose enough cost on the suppliers per taxpayer dollar spent, it could be cost-effective. Most analyses find that it is costly to fight this arms race in a mature market, as an excerpt from a simple static portion of Caulkins et al.'s (1997) model suggests.

Assume the demand curve can be locally linearized with a known elasticity $\eta$, that the market is in equilibrium in the sense that suppliers' revenues just cover costs, including normal profits, and that the industry supply curve stems from the following cost structure. "Normal" business costs per unit increases linearly in volume (i.e., they follow a textbook upwardly sloping linear supply curve, but there are two additional costs: (1) costs imposed by enforcement including compensation for the risks of arrest and imprisonment and (2) costs that are linear in the dollar value of the drugs distributed, not their weight. The last term is important because drug distribution is almost pure brokerage activity, requiring minimal processing and the drugs weigh next to nothing per unit value. (Cocaine and heroin sell at retail for about ten and one hundred times their weight in gold.) Thus the suppliers' costs of delivering drugs can be written as

Total cost $=\left(c_{0}+c_{1} Q\right) Q+E+\gamma(P Q)$, where $\mathrm{P}$ and $\mathrm{Q}$ are the market clearing price and quantity, $\mathrm{E}$ is the enforcement "tax", and $\mathrm{c}_{0}, \mathrm{c}_{1}$, and $\gamma$ are positive constants. With a little algebra (Caulkins, 1997, Appendix C) it is easy to show that shifts in demand and the enforcement tax have the following effects on the market equilibrium:

\begin{tabular}{|c|c|c|}
\hline & \multicolumn{2}{|c|}{ If there is a: } \\
\hline $\begin{array}{c}\text { Resulting Percentage } \\
\text { Change in }\end{array}$ & $\begin{array}{c}\text { 1\% Increase in Costs that } \\
\text { Enforcement Imposes on Dealers }\end{array}$ & 1\% Increase in Demand \\
\hline Consumption & $\frac{\beta \eta}{1-\gamma+\left(\beta-\alpha_{1}\right) \eta}$ & $\frac{1-\gamma}{1-\gamma+\left(\beta-\alpha_{1}\right) \eta}$ \\
\hline Price & $\frac{\beta}{1-\gamma+\left(\beta-\alpha_{1}\right) \eta}$ & $\frac{\alpha_{1}-\beta}{1-\gamma+\left(\beta-\alpha_{1}\right) \eta}$ \\
\hline Spending & $\frac{\beta(1+\eta)}{1-\gamma+\left(\beta-\alpha_{1}\right) \eta}$ & $\frac{1-\gamma-\left(\beta-\alpha_{1}\right)}{1-\gamma+\left(\beta-\alpha_{1}\right) \eta}$ \\
\hline
\end{tabular}

where $\alpha_{0}=\mathrm{c}_{0} / \mathrm{P}_{0}, \alpha_{1}=\mathrm{c}_{1} \mathrm{Q}_{0} / \mathrm{P}_{0}$, and $\beta=\mathrm{E}_{0} / \mathrm{P}_{0} \mathrm{Q}_{0}$ are the fractions of dealers' costs in the current equilibrium that are attributable to the linear part of the cost term above, the quadratic part of the cost term, and enforcement, respectively. Since $\gamma$ is the remaining fraction, $\alpha_{0}+\alpha_{1}+$ 
$\beta+\gamma=1$, so one of these parameters $\left(\alpha_{0}\right)$ can be eliminated in the expressions above. Caulkins et al. (1997) estimate that for the US cocaine industry in 1992, $\eta=-1, \alpha_{0}=0.55, \alpha_{1}=0, \gamma=$ 0.25 , and $\beta=0.2$. Suppose these parameters still apply in 2000, when ONDCP (2001) estimates that there were 3.035 million occasional and 2.707 chronic cocaine users who collectively spent $\$ 35.3$ billion while consuming 259 metric tons of cocaine.

Reducing equilibrium consumption by $1 \%$ would require imposing costs of $\left(\alpha_{1}-\beta-(1-\right.$ $\gamma) / \eta) 1 \% * \$ 35.3$ billion $=\$ 194$ million on suppliers. How much it costs taxpayers to "purchase" this cost-imposition depends on how efficient enforcement is, but consider a policy of giving longer sentences to people who already would have been convicted and incarcerated at least briefly. (Thus we can ignore details of arrest, adjudication, seizures, etc.) Suppose drug suppliers have to increase workers' wages by $\$ 50,000$ to compensate them for the risk of each additional expected year of incarceration. It costs taxpayers about $\$ 25,000$ to incarcerate someone for a year (Greenwood et al., 1994), so the efficiency ratio is 2:1 and taxpayers could buy that $1 \%$ reduction in cocaine consumption for $\$ 97$ million per year.

Alternately, one could cut consumption by $1 \%$ by reducing demand by $1+\eta\left(\beta-\alpha_{1}\right) /(1$ $-\gamma)=0.73 \%$. Assuming heavy users consume seven times as much capita as do light users, that would require eliminating $0.73 \% *(2.707+3.035 / 7)=23,000$ heavy users. At first this might seem to be the more expensive route. $\$ 97$ million would only pay for about two treatment admissions per person for 23,000 heavy users. However, the supply reduction strategy requires spending $\$ 97$ million per year indefinitely. If the 23,000 heavy users were somehow removed by treating each twice, that would reduce consumption by $1 \%$ indefinitely (ignoring indirect effects on initiation, which may be a second-order effect in a mature market). At a $4 \%$ discount rate, the present value of $\$ 97$ million per year forever is $\$ 2.4$ billion, or about $\$ 100,000$ for each of those 23,000 users, enough for some two dozen rounds of treatment per person.

There is a sharp distinction between the timing of the costs and benefits of enforcement and treatment. Raising prices by threatening sanctions brings immediate benefits, since suppliers have to adjust their cost structure in the short run. There are also some long-lasting benefits because raising prices today suppresses initiation and increases quitting thereby reducing future demand, but those effects are secondary. The costs of enforcement with conventional sentences fall mainly in the first year or two, but the longer the sentence, the longer the period over which costs to taxpayers are spread. Furthermore, if the policy change is extending the sentence of someone who would have been incarcerated anyhow, the incremental costs do not begin to be felt until after the end of the baseline sentence. By contrast, with treatment, the costs are all upfront, as are the "incapacitation" benefits during treatment, but the benefits of convincing someone to quit continue to accrue throughout the entire period during which they would have otherwise continued to consume.

Rydell and Everingham (1994) and Caulkins et al. (1997) examine the timing of the benefits and costs of various interventions in detail. Roughly speaking the result is the following. Suppose a treatment intervention and an enforcement intervention that imposes costs on suppliers over the next twelve months each have the same impact on consumption over the next 15 years, discounting future outcomes at $4 \%$ per year. The treatment intervention would have about double the impact on consumption in the first year as it would in each succeeding year, whereas the ratio for enforcement is about nine to one. Looking at it another way, the enforcement intervention has about 2.7 times as great an impact on consumption in the first year as does treatment, whereas in every succeeding year the treatment program would have 1.65 
times as much impact as the enforcement program. Hence, although treatment may be the more effective way to reduce use in the long run, if there is some great need to reduce consumption in the next year or two, enforcement has greater capacity to focus its benefits in the present.

One concern with price-raising enforcement is that it might increase crime even if it reduces use. Most drug-related crime is economic-compulsive" (committed to obtain money to buy drugs) or "systemic" (arising from drug selling, e.g., punishment for non-payment) and so is driven by drug dollars, not by intoxication or use per se (also called "psychopharmacological" drug-related crime). Hence, depending on the elasticity of demand, driving up prices could actually increase not decrease drug-related crime. A very simple model of this conveys the basic intuition. Suppose that drug-related crime is proportional to a weighted sum of drug use and spending on drugs, with the latter accounting for $100 \mathrm{x} \%$ of the total. So drug-related crime

$$
\mathrm{C}=\mathrm{k}_{1} \mathrm{P} \mathrm{Q}+\mathrm{k}_{2} \mathrm{Q} \text {, }
$$

for some positive constants $\mathrm{k}_{1}$ and $\mathrm{k}_{2}$ such that $\mathrm{k}_{1} \mathrm{P} \mathrm{Q}=\mathrm{x}\left(\mathrm{k}_{1} \mathrm{P} \mathrm{Q}+\mathrm{k}_{2} \mathrm{Q}\right)$, i.e., $\mathrm{k}_{1} \mathrm{P} / \mathrm{k}_{2}=\mathrm{x} /(1-\mathrm{x})$. Taking the derivative of crime with respect to price gives

$$
\begin{aligned}
\mathrm{dC} / \mathrm{dP} & =\mathrm{k}_{1} \mathrm{Q}+\left(\mathrm{k}_{1} \mathrm{P}+\mathrm{k}_{2}\right) * \mathrm{dQ} / \mathrm{dP} \\
\frac{d C}{d P} & =k_{1} Q+\left(k_{1} P+k_{2}\right) \frac{d Q}{d P} \\
& =\frac{k_{2} Q}{P}\left(\frac{x}{1-x}+\left(\frac{x}{1-x}+1\right) \frac{d Q}{d P} \frac{P}{Q}\right) \\
& =\frac{k_{2} Q}{P(1-x)}(x+\eta)
\end{aligned}
$$

So driving up prices reduces drug related crime if the absolute value of the elasticity of demand $(|\eta|)$ is greater than $\mathrm{x}$, the proportion of drug-related crime that is driven by drug spending rather than drug use.

Figure 3 uses the market equilibrium model above, to illustrate in more detail how the effect price-raising enforcement and demand reduction have on drug use, spending, and crime depend on the elasticity of demand. ${ }^{8}$

Figure 3: Relative Effectiveness of Demand Reduction and Price-Raising Enforcement Depends on the Flasticity of Demand for Druos

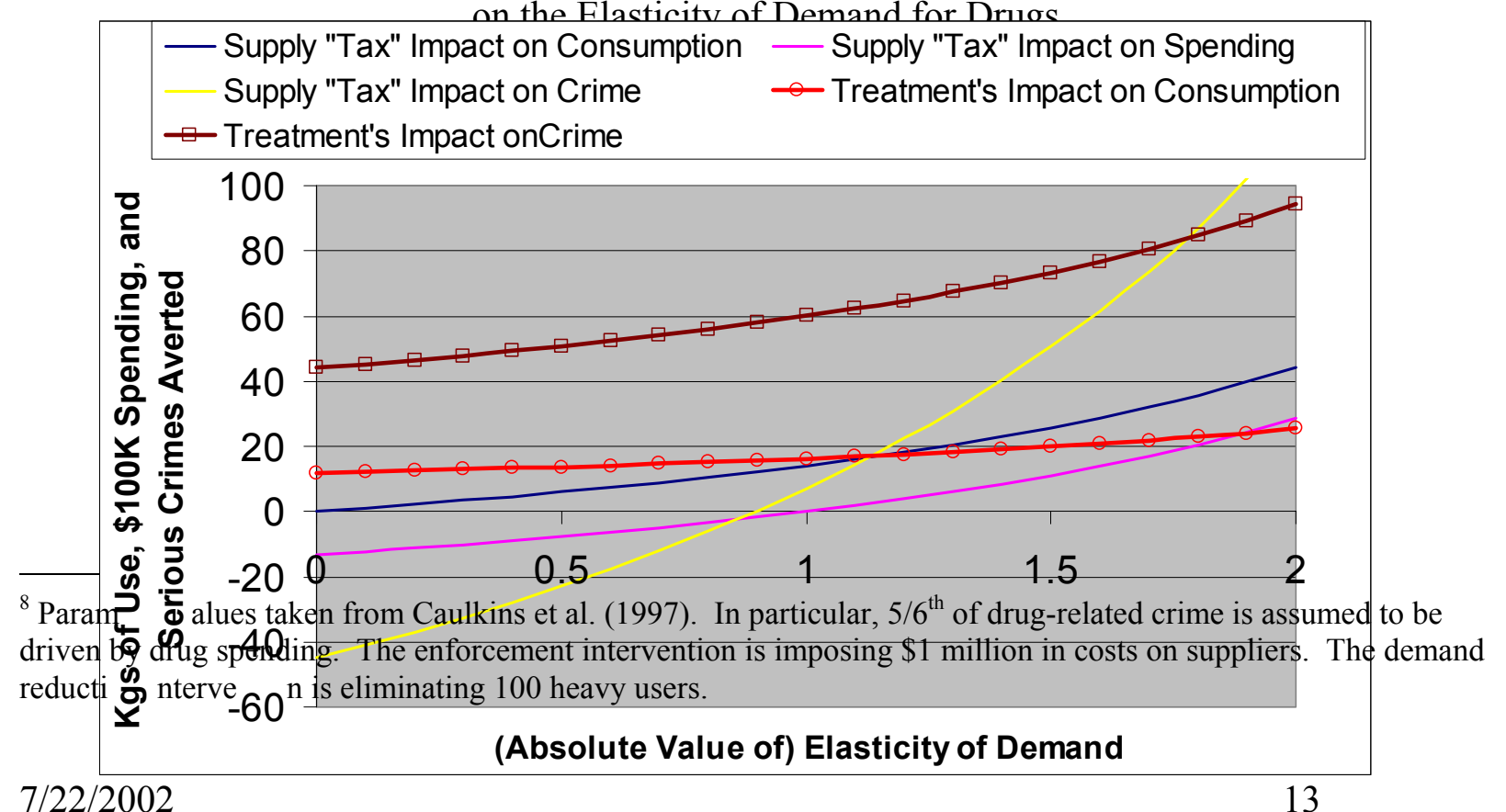




\section{Dynamic/Epidemic Modeling Results}

Drug use varies dramatically over time, driven in no small part by endogenous nonlinear dynamics, not just in response to changes in policy or exogenous factors such as the poverty rate. Hence, one would expect the effectiveness of interventions to likewise vary with the state of the epidemic, and a growing literature investigates this possibility. According to this school of thought, it is rarely sensible to make statements such as "treatment is better than enforcement" or vice versa without qualifying the statement (e.g., "better for controlling cocaine use in the US now that the epidemic has plateaued").

Perhaps the most important endogenous dynamic is the "contagious" character of drug initiation. There is not literally a pathogen as with cholera or malaria, but drug use is contagious in the sense that drug use spreads when non-users are introduced to the drug by current users. (Contrary to once popular myth, most initiation does not stem from dealers "pushing" the drugs on potential users.) In formal terms, there is a positive feedback from current use to initiation. Systems with such a feedback can grow explosively.

There are several models of how that explosive growth ends, depending in part on what country and drug is being modeled. In a line of modeling pioneered by Tragler (Tragler et al., 2001; Caulkins et al. 2000; 2002 - Karen's masters thesis) a steady state emerges when quitting at a constant per capita rate balances initiation which is an increasing but concave function of use.

In a line of models pioneered by Behrens (Behrens et al., 1999, 2000, 2001) the key negative feedback is reputational. As some early initiates progress from light to heavy use, the drug's dangers become apparent and initiation declines. That decline coupled with the high quit rates for light users increases the ratio of heavy to light users, further enhancing the drug's negative reputation and cutting initiation. These models can, for some parameter values, generate recurrent cycles of drug epidemics. Almeder (Almeder et al., 2001, forthcoming) has examined a related family of age-distributed models in which the nature and intensity of the reputational feedback depends on the relative and absolute ages of the users and potential users.

In a line of model associated with Rossi and colleagues (e.g., Rossi, 1999, 2001), the limiting factor is the number of susceptibles. To over-simplify, essentially everyone who might try the drug ends up trying it. Most use only briefly, but some get hooked, so after the explosive growth stage there is a decline to an endemic problem characterized by a high proportion of heavy users.

The overall policy prescription from these models is: Rely on enforcement early and treatment later in the epidemic. Prevention can be extraordinarily cost-effective if done ahead of the epidemic; later it is much less effective, but is still worth doing . In particular, keeping prices high initially is a useful way to slow the explosive spread, but later on high prices are costly to maintain and may exacerbate drug-related crime. More generally, one should initially fight very aggressively to contain the epidemic. Ideally it would be eradicated or stabilized at low levels, but if the intervention is too late or the "power" of the epidemic growth too great, then one 
should accommodate the growth in drug use by gradually shifting to strategies that remove heavy users and/or ameliorate the social cost per heavy user.

Perhaps the most visually compelling variant of this basic theme is provided by Tragler et al. (2001). The model seeks the optimal dynamic levels of price-raising enforcement and drug treatment that together minimize the present value of the weighted sum of the quantity of drugs consumed and the control spending, subject to drug use evolving according to the following nonlinear differential equation model of drug use. Initiation is concave in use. "Natural" quitting is at a constant rate per capita, which can be augmented by treatment, although with diminishing efficiency as the proportion of users in treatment increases. Prices affect all flow rates and are in turn a function of the intensity of price-raising enforcement as above.

In Figure 4, the horizontal axis depicts the number of users and the vertical axis enforcement spending. There is a so-called Dechert-Nishimura-Skiba (DNS) threshold when the number of users is . If the initial number of users is to its left (i.e., control begins before the epidemic has passed this point), the optimal strategy is to use massive levels of enforcement (and treatment - not shown in the figure) to drive use back to some minimal level. Otherwise, it is optimal to let use grow toward a positive equilibrium. In that case enforcement spending should increase with use, but not proportionately - as should treatment spending. As a result, the proportion of control spending allocated to treatment increases over time. This finding of a sharp choice between eradication and accommodation at the aggregate level is consistent with others' analyses of enforcement's impact on local drug markets (e.g., Baveja et al. 1993, 1997; Naik et al., 1996; Kort et al., 1998).

Figure 4: Tragler's Finding that If Control Catches the Epidemic Early It Should Seek to Eradicate the Epidemic, Otherwise Accommodation is the Optimal Strategy 
For initial states $A_{0}$ below $A_{D N S}$ it is optimal to "eradicate" drug use, while above $A_{D N S}$ a steady state with a high number of users turns out to be optimal

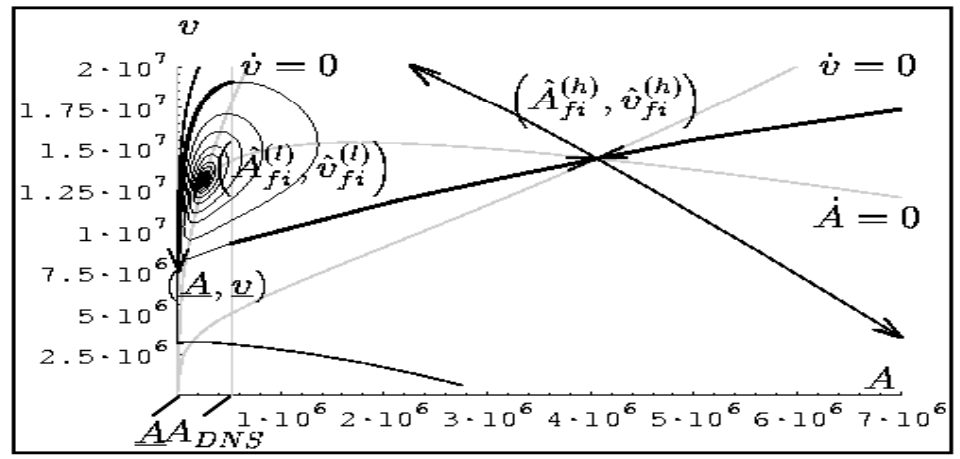

ADNS ... Dechert-Nishimura-Skiba threshold

\begin{tabular}{|c|c|}
\hline$\underline{A}$ & $\hat{A}_{f i}^{(h)}$ \\
\hline
\end{tabular}


A key driver of this dynamic is "enforcement swamping" (Kleiman, 1993).

Enforcement's deterrent or price-raising potential depends on its intensity - i.e., the amount of enforcement per kilogram or per person in the market - not the amount of enforcement. Early, when the market is small, it is not so hard to achieve high enforcement intensity, but doubling the market size halves the intensity of a given enforcement level by spreading it over a larger target. Since drug use can much more than double over an epidemic, overcoming this dilution for an established mass market drug is very costly.

One of the more interesting insights to emerge from these optimal control models comes from Behrens et al.'s (1997a, 1999) complementary analysis of prevention and treatment. It extends Everingham and Rydell's (1994) model of cocaine use in Figure 1 to make initiation increasing in the number of light users and decreasing in the number of heavy users. Insights deriving from this model include: (1) Prevention is most valuable when there are relatively few heavy users, e.g. in the beginning of an epidemic. Treatment is more effective later. (2) The transition period when it is optimal to use both prevention and treatment is very brief. (3) Total social costs increase dramatically if control is delayed.

The second of these is particularly interesting because so many people describe the strategic drug policy choice as concerning supply-side or demand-side interventions, but Behrens et al. show that it is misleading to lump together treatment and prevention even though they both affect demand. At any given point in an epidemic, prevention might be very valuable but not treatment or vice versa. Indeed, when Behrens et al.'s model is parameterized for the US cocaine epidemic and school-based prevention (which has a roughly 8-year lag between program spending and effect on initiation), it is literally never optimal to spend money on both prevention and treatment! (See Figure 5.) That absence of overlap is not robust with respect to parameter variation, and as discussed above, prevention is probably justified on an on-going basis because of its impact on the use of other drugs. Nevertheless, the general message is robust: It is simplistic to argue for or against "demand-side" (or "supply-side") strategies without knowing more about the specific mix of strategies and the current state of the epidemic in question.

Figure 5: Optimal Cocaine Control Spending Levels over Time for School-Based Prevention and Treatment for the Past US Cocaine Epidemic 


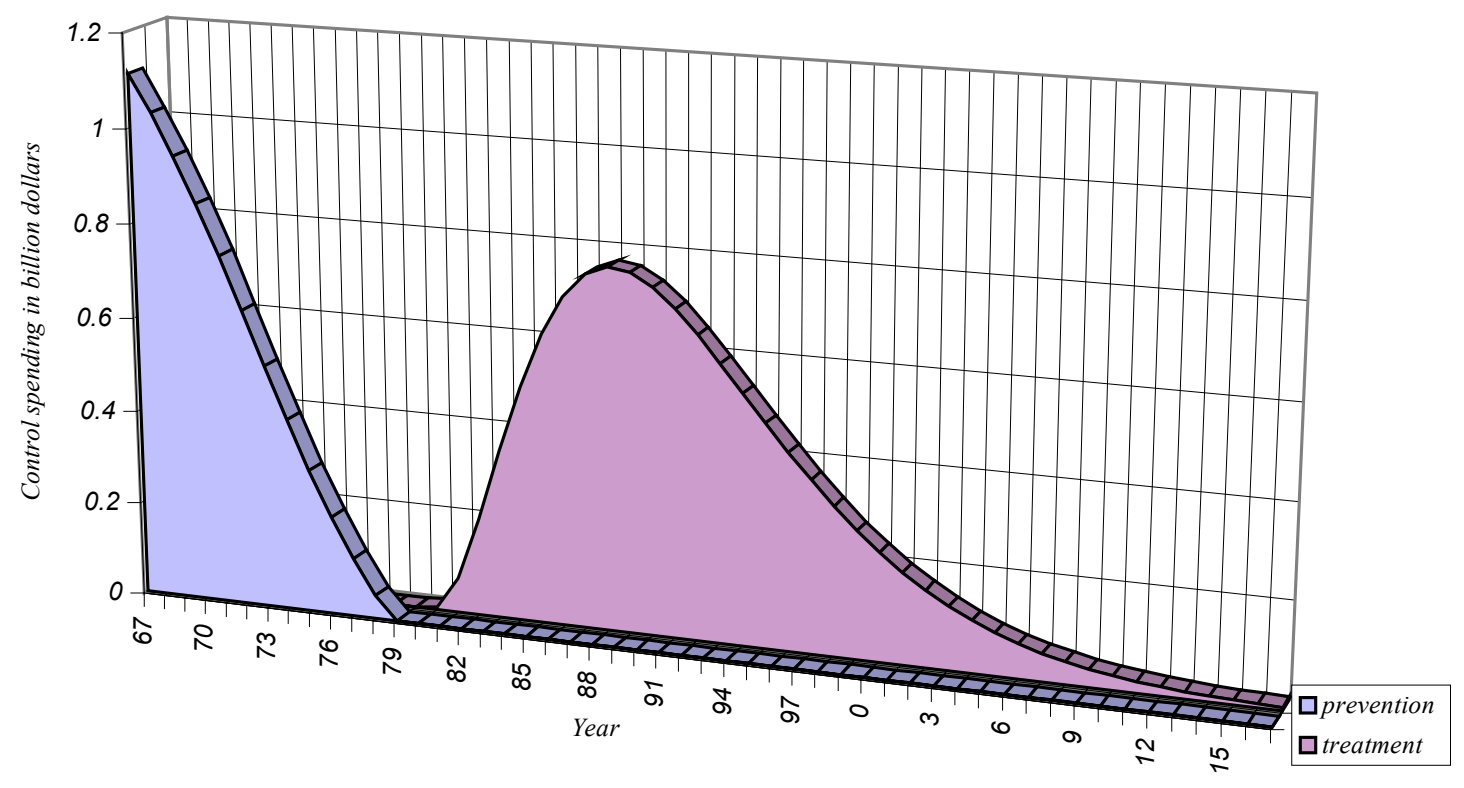

\section{Opportunities for Further Research}

Drug policy is an important domain. It has enough nonlinearities from epidemic feedback and market dynamics to challenge unguided intuition, so formal mathematical models such as those reviewed here can be a very important aid to strategic planning. There remains, however, far more that is not known than is known, so possibilities for further research are great.

There are multiple drugs that interact in many ways. At the lowest level, drugs interact in users' bodies so that drugs taken in combination can lead to overdose even when larger doses of each drug individually would not. At the level of a drug use career, there are multiple hypotheses concerning how use of one drug can affect use of others, both in the narrow sense of being consumption substitutes or complements and in the broader sense. E.g., use of one substance can bring an individual into contact with users and sellers of other drugs. There are also interactions at the market level. E.g., the presence of established distribution networks for one drug (e.g., Colombian cocaine) can facilitate the spread of another drug (e.g., Colombian heroin), and control resources devoted to one drug may not be available for another.

Dependent users often have multiple medical conditions. Many are "dually diagnosed" with mental health as well as substance abuse disorders. Many are infected with HIV or Hepatitis C. There can be complicated interactions both in terms of treatment regimens (how successful will dependent users be in complying with complicated HIV control regimens? - cf. Turner et al., 2001) and treatment financing (cost containment pressures may encourage restrictions on drug treatment, but resumption of drug use can increase other health care costs in the long run - cf. Sturm et al., 1999; Sturm and Pacula, 2000). In some sense it makes more sense to think about the cost-effectiveness of drug treatment relative to the cost-effectiveness of other medical interventions than it does to compare drug treatment to criminal justice or prevention interventions. 
Drug policy intersects not only with health and crime, but also with social policy more generally (Boyum and Reuter, 2001). For example, the issues of the dually diagnosed are particularly problematic for those who are also homeless (Stecher et al., 1995).

Perhaps the greatest need, though, is for more fundamental understanding of how drug epidemics evolve. This is perhaps best gained by modeling more epidemics, both at lower levels of geographic aggregation (e.g., in individual cities within the US) and in other countries. A defining characteristic of nonlinear systems is that the magnitude of the response to a given intervention is nonlinear. Sometimes the response is less than proportionate; sometimes it is much more. Often interventions have seemed to produce less than hoped for effects. It may be that all these interventions have been poorly conceived or executed, but an alternative explanation is that they simply have not been "timed" appropriately because the nonlinear character of the underlying epidemics has not been fully appreciated. In this alternate, more optimistic view, advances in understanding of drug epidemics will not only help us choose the best among a range of interventions each with mediocre performance, but also help enhance the effectiveness of all interventions.

\section{References}

Almeder, Christian, Jonathan P. Caulkins, Gustav Feichtinger, and Gernot Tragler. 2001. "Age-specific Multi-State Initiation Models: Insights from Considering Heterogeneity." Bulletin on Narcotics, Vol. 53, No. 1, pp.105-118

Almeder, Christian, Jonathan P. Caulkins, Gustav Feichtinger, and Gernot Tragler. forthcoming. "An Age-Structured Single-State Drug Initiation Model - Cycles of Drug Epidemics and Optimal Prevention Programs." Socio-Economic Planning Sciences,

Bartlett, J. C., L. S. Miller, D. P. Rice, and W. B. Max, "Medical Care Expenditures Attributable to Cigarette Smoking_-United States 1994," MMWR, Vol. 43, 1994, pp. 469-72.

Baveja, Alok, Rajan Batta, Jonathan P. Caulkins, and Mark H. Karwan. 1993. "Modeling the Response of Illicit Drug Markets to Local Enforcement." Socio-Economic Planning Sciences, Vol. 27, No. 2, pp.73-89. ${ }^{9}$

Baveja, Alok, Jonathan P. Caulkins, Wensheng Liu, Rajan Batta, and Mark H. Karwan. 1997. "When Haste Makes Sense: Cracking Down on Street Markets for Illicit Drugs." SocioEconomic Planning Sciences, Vol. 31, No. 4, pp.293-306.

Behrens, D.A., J. P. Caulkins, G. Tragler, and G. Feichtinger, "Controlling the U.S. Cocaine Epidemic: Prevention from Light vs. Treatment of Heavy Use.” Working Paper 214, (1997) Vienna University of Technology, Vienna.

Behrens, D.A., J.P. Caulkins, G. Tragler, J. Haunschmied, and G. Feichtinger, "A Dynamic Model of Drug Initiation: Implications for Treatment and Drug Control." Mathematical Biosciences, 159(1999):1-20.

Blumstein, A. and D. Cork (_ _Linking Gun Availability to Youth Gun Violence," Law and Contemporary Problems, Vol. 5, No. 1, pp.5-24.

Botvin, Gilbert J., E. Baker, L. Dusenbury, E.M. Botvin, and T. Diaz, "Long-Term Follow-Up Results of a Randomized Drug Abuse Prevention Trial in a White Middle-Class Population," Journal of the American Medical Association, 273(1995):1106-1112.

\footnotetext{
${ }^{9}$ Cite on original page 53 was Baveja et al. 1992. Should have been to 1992.
} 
Boyum, D, "Reflections on Economic Theory and Drug Enforcement," doctoral dissertation, Harvard University, Cambridge, MA 1992.

Boyum, D. and P. Reuter. 2001. "Reflections on Drug Policy and Social Policy". in Philip B. Heymann and William N. Brownsberger, eds., Drug Addiction and Drug Policy. Cambridge, Mass: Harvard University Press.

Caulkins, J.P., "The Distribution and Consumption of Illicit Drugs: Some Mathematical Models and Their Policy Implications," doctoral dissertation, MIT, Cambridge, MA, 1990.

“Developing Price Series for Cocaine.” MR-317-DPRC, Santa Monica: RAND, 1994.

Caulkins, Jonathan P. 1993a. "Zero-Tolerance Policies: Do They Inhibit or Stimulate Illicit Drug Consumption?” Management Science, Vol. 39, No. 4, pp.458-476.

Caulkins, Jonathan P. 1993b. "Local Drug Markets' Response to Focused Police Enforcement." Operations Research, Vol. 41, No. 5, pp.848-863.

Caulkins, Jonathan P. and Rema Padman. 1993a. "Quantity Discounts and Quality Premia for Illicit Drugs." The Journal of the American Statistical Association. Vol. 88, No. 423, pp.748-757.

Caulkins, Jonathan P. and Rema Padman. 1993b. "Interdiction's Impact on the Structure and Behavior of the Export-Import Sector for Illicit Drugs." Zeitschrift fur Operations Research, Vol. 37, pp.207-224.

Caulkins, Jonathan P. 1997. “How Prevalent Are 'Very Light' Drug Users?” Federation of American Scientists' Drug Policy Analysis Bulletin, Issue Number 3, pp.3-5.

Caulkins, Jonathan P. 1997b. "Modeling the Domestic Distribution Network for Illicit Drugs," Management Science, Vol. 43, No. 10, pp.1364-1371.

Caulkins, Jonathan P. 2001. "The Relationship Between Prices and Emergency Department Mentions for Cocaine and Heroin.” American Journal of Public Health, Vol., 91, No. 9, pp.1446-1448.

Caulkins, Jonathan P., Maria Dworak, Gustav Feichtinger, and Gernot Tragler. 2000. "Drug Enforcement and Property Crime: A Dynamic Model." Journal of Economics, Vol. 71, No. 3, pp.227-253.

Caulkins, Jonathan P., C. Peter Rydell, Susan S. Everingham, James Chiesa, and Shawn Bushway. 1999. An Ounce of Prevention, a Pound of Uncertainty: The CostEffectiveness of School-Based Drug Prevention Program MR-923-RWJ, RAND, Santa Monica, CA.

Caulkins, Jonathan P., Susan Paddock, Rosalie Pacula, and James Chiesa. 2002. School-Based Drug Prevention: What Kind of Drug Use Does it Prevent? MR-1459-RWJ. RAND, Santa Monica, CA.

Caulkins, Jonathan P. and Rema Padman, "Quantity Discounts and Quality Premia for Illicit Drugs." The Journal of the American Statistical Association, 88(1993a):748-757.

Caulkins, Jonathan P. and Rema Padman. 1993b. "Interdiction's Impact on the Structure and Behavior of the Export-Import Sector for Illicit Drugs." Zeitschrift fur Operations Research, Vol. 37, pp.207-224.

Caulkins, J.P. and P. Reuter, "Setting Goals for Drug Policy: Harm Reduction or Use Reduction.” Addiction, 92(1997):1143-1150.

, "What Price Data Tell Us About Drug Markets." Journal of Drug Issues.

28(1998):593-612. 
Caulkins, Jonathan P., C. Peter Rydell, William L. Schwabe, and James Chiesa. 1997. Mandatory Minimum Drug Sentences: Throwing Away the Key or the Taxpayers' Money? MR-827-DPRC, RAND, Santa Monica, CA.

Centers for Disease Control and Prevention (CDCP). HIV/AIDS Surveillance Report, 2001. 13(No.1), CDC, Atlanta, GA.

Chaloupka FJ, Pacula RL. Economics and anti-health behavior: the economic analysis of substance use and abuse. In: Bickel W, Vuchinich R, eds. Reframing Health Behavior Change with Behavioral Economics. Hillsdale, NJ: Lawrence Earlbaum Associates; 2000: 89-111.

Childress, Michael, A Systems Description of the Heroin Trade, RAND, MR-234-A/DPRC, 1994a.

Childress, Michael, A Systems Description of the Marijuana Trade, RAND, MR-235-A/DPRC, 1994b.

Cohen, Jacqueline, Wilpen Gorr, and Piyusha Singh (2002) "Estimating Intervention Effects in Varying Risk Settings: Do Police Raids Reduce Illegal Drug Dealing at Nuisance Bars, Criminology.

Crane, B.D., A.R. Rivolo, and G.C. Comfort. 1997. An Empirical Examination of Counterdrug Interdiction Program Effectiveness. Alexandria, Virginia: Institute for Defense Analysis.

Crawford, G.B., P. Reuter, with K. Isaacson and P. Murphy, Simulation of Adaptive Response: A Model of Drug Interdiction. Santa Monica: RAND, 1988.

Dawid, H. and G. Feichtinger, "Optimal Allocation of Drug Control Efforts: A Differential Game Analysis," Journal of Optimization Theory and Applications, 91(1996):279-297.

DeSimone, Jeff. In Submission. "The Relationship Between Illegal Drug Prices at Different Market Levels."

Dombey-Moore, Bonnie, Susan Resetar, and Michael Childress, A Systems Description of the Cocaine Trade. Santa Monica: RAND, 1994.

DuPont, Robert L., and Mark H. Greene. 1973. "The Dynamics of a Heroin Addiction Epidemic." Science 181:716-22.

Ellickson, Phyllis L. and Robert M. Bell, "Drug Prevention in Junior High: A Multi-Site Longitudinal Test," Science, 247 (March 1990):16-248.

EMCDDA (2001) Modelling Drug Use: Methods to Quantify and Understand Hidden Processes, Luxembourg: Office for Official Publications of the European Communities.

Epstein, J.F. and J.C. Gfroerer. 1998. "Changes Affecting NHSDA Estimates of Treatment Need for 1994-1996," in Substance Abuse and Mental Health Services Administration, Rockville, MD, Analyses of Substance Abuse and Treatment Need Issues, Analytical Series Document A-7.

Everingham, Susan S. and C. Peter Rydell. 1994. Modeling the Demand for Cocaine, MR-332ONDCP/A/DPRC. RAND, Santa Monica, CA.

Fent, Thomas, Gustav Feichtinger, and Gernot Tragler. 2002. "A Dynamic Game of Offending and Law Enforcement," International Game Theory Review, Vol. 4, No. 1, pp.71-89.

Feichtinger, Gustav, Waltraud Grienauer, and Gernot Tragler. 2002. „Optimal Dynamic Law Enforcement,“"European Journal of Operations Research, No. 141, pp.58-69. 
Gardiner, L. K. and R. C. Shreckengost. 1987. A System Dynamics Model for Estimating Heroin Imports into the United States. System Dynamics Review. 3, 8-27.

Gerstein, D.R., R.A. Johnson, H.J. Harwood, D. Fontain, N. Suter and K. Malloy. Evaluating Recovery Services: The California Drug and Alcohol Treatment Assessment, Chicago: National Opinion Research Center and Fairfax: Lewin-VHI, 1994.

Gorr, W.L. and A. Olligschlaeger, "Weighted Spatial Adaptive Filtering: Monte Carlo Studies and Application to Illicit Drug Market Modeling," Geographical Analysis, Vol. 26, No. 1 (January 1994), pp 67-87.

Gragnani, A., S. Rinaldi, and G. Feichtinger, "Dynamics of Drug Consumption: a Theoretical Model," Socio-Economic Planning Sciences, 31(1997).

Harwood, H., D. Fountain, and G. Livermore, The Economic Costs of Alcohol and Drug Abuse in the United States, 1992, Washington, D.C.: U.S. Department of Health and Human Services, 1998.

Homer, Jack B., "A System Dynamics Model for Cocaine Prevalence Estimation and Trend Projection," The Journal of Drug Issues, 23(Spring 1993a):251-279.

, "Projecting the Impact of Law Enforcement on Cocaine Prevalence: A System Dynamics Approach," The Journal of Drug Issues, 23(1993b):281-295.

Hser, Yih-Ing, M. Douglas Anglin, Thomas D. Wickens, Mary-Lynn Brecht, and Jack Homer, "Techniques for the Estimation of Illicit Drug-Use Prevalence: An Overview of Relevant Issues." Washington, D.C.: National Institute of Justice, 1992.

Institute of Medicine. Pathways of Addiction: Opportunities in Drug Abuse Research. Washington D.C.: National Academy Press, 1996.

Kahan, James P., C. Peter Rydell, and John Setear, "A Game of Urban Drug Policy," Peace and Conflict: Journal of Peace Psychology, 1(3),275-290, 1995. (RAND Reprint RP-459.)

Kahan, James P., John Setear, M.M. Bitzinger, S.B. Coleman, and J. Feinleib, Developing Games of Local Drug Policy, RAND, N-3395-DPRC, 1992.

Kaplan, Edward H. and Mira Johri. 2000. "Treatment on Demand: An Operational Model," Health Care Management Science, Vol. 3, pp.171-183.

Kaya, C.Y., Y. Tugai, and J.A. Filar. 2001. Heroin Use in Australia: Population Trends. Working Paper, University of South Australia.

Kennedy, Michael, Peter Reuter, and Kevin Jack Riley, "A Simple Economic Model of Cocaine Production," Mathematical and Computer Modelling, 17(2):19-36, 1993. (RAND Reprint $\underline{\text { RP-191.) }}$ More detailed version published as RAND Report MR-201-USDP, 1994.

Kleiman, Mark A.R., “Against Excess: Drug Policy for Results.” Basic Books, New York, 1992.

Knoll, Claudia and Doris Zuba (2002). Masters Thesis at the Technical University of Vienna.

Kort, P. M., G. Feichtinger, R. F. Hartl and J. L. Haunschmied, "Optimal Enforcement Policies (Crackdowns) on an Illicit Drug Market," Optimal Control Applications \& Methods, 19(1998):169-184.

Law, Matthew G, Gregory J Dore, Nicky Bath, Sandra Thompson, Nick Crofts, Kate Dolan, Wendy Giles, Paul Gow, John Kaldor, Stuart Loveday, Elizabeth Powell, Jenean Spencer ${ }^{1}$, and Alex Wodak. In Submission. Modeling Hepatitis C Virus Incidence, Prevalence, and Long-Term Sequelae in Australia, 2001.

Levin, G., E. B. Roberts, and G. B. Hirsch. 1975. The Persistent Poppy: A Computer-Aided Search for Heroin Policy. Ballinger Publishing Company, Cambridge, MA. 
MacCoun, Robert J., Peter Reuter, and Thomas Schelling, "Assessing Alternative Drug Control Regimes," Journal of Policy Analysis and Management, 15(1996):330-352.

MacCoun, Robert J. and Peter Reuter (2001) Beyond the Drug War: Learning from Other Times, Places, and Vices. New York: Cambridge University Press.

Maher, L, \& Dixon, D. 1999, 'Policing and Public Health', British Journal of Criminology, vol. 39 , no. 4, pp.488-511.

Maher, L. \& Dixon, D. 2001, 'The Cost of Crackdowns: Policing Cabramatta's Heroin Market' Current Issues in Criminal Justice, vol. 13, no. 1, pp.5-22.

Manski, Charles F., John V. Pepper, and Carol V. Petrie (eds.) 1999. Assessment of Two CostEffectiveness Studies on Cocaine Control Policy. National Academy Press, Washington, DC.

Manski, Charles F., John V. Pepper, and Carol V. Petrie (eds.) 2001. Informing America's Policy on Illegal Drugs: What We Don't Know Keeps Hurting Us. National Academy Press, Washington, DC.

Naik, A.V., A. Baveja, R. Batta, and J.P. Caulkins, "Scheduling Crackdowns on Illicit Drug Markets." European Journal of Operational Research, 88(1996):231-250.

Office of National Drug Control Policy. Various years. The National Drug Control Strategy. The White House, Washington, D.C.

Pentz, Mary Ann, "Cost, Benefits, and Cost-Effectiveness of Comprehensive Drug Abuse Prevention," in Cost-Benefit/Cost-Effectiveness Research of Drug Abuse Prevention: Implications for Programming and Policy, NIDA Research Monograph \#176, U.S. Department of Health and Human Services, Washington, D.C., 1998:111-129.

Pollack, Harold. (Forthcoming) "Methadone Maintenance as HIV Prevention: CostEffectiveness Analysis," in Quantitative Evaluation of HIV Prevention Programs, E.H. Kaplan and R. Brookmeyer, eds., Yale University Press, New Haven, CT.

Prendergast, Michael, Deborah Podus, and Kai McCormack, "Bibliography of Literature Reviews on Drug Abuse Treatment Effectiveness." Journal of Substance Abuse Treatment. 15(1998):267-270.

Reuter, Peter. "Disorganized Crime: The Economics of the Visible Hand." Cambridge, MA: MIT Press, 1983. , “Eternal Hope: America's International Narcotics Efforts. The Public Interest, (1985). , "Quantity Illusions and Paradoxes of Drug Interdiction: Federal Intervention into Vice Policy. Law and Contemporary Problems, 51(1988):233-252.

Reuter, P. and M.A.R. Kleiman, "Risks and Prices: An Economic Analysis of Drug Enforcement." in Crime and Justice: An Annual Review of Research Vol. 7, ed. M. Tonry and N. Morris. Chicago: University of Chicago Press, 1986:289-340.

Reuter, P., R. MacCoun, and P. Murphy. Money From Crime: A Study of the Economics of Drug Dealing in Washington, D.C. Santa Monica: RAND, 1990.

Rice, D.P., S. Kelman, L.S. Miller, and S. Dunmeyer, "The Economic Costs of Alcohol and Drug Abuse and Mental Illness: 1985." San Francisco: Institute for Health and Aging, University of California, 1990.

Rossi, Carla. 1999. "Estimating the Prevalence of Injection Drug Users on the Basis of Markov Models of the HIV/AIDS Epidemic: Applications to Italian Data," Health Care Management Science, Vol. 2, pp.173-179. 
Rossi, Carla. 2001. "A Mover-Stayer Type Model for Epidemics of Problematic Drug Use," Bulletin on Narcotics, Vol. 53, No. 1, pp.39-64.

Rydell, C.P. and S.S. Everingham, “Controlling Cocaine. Supply Versus Demand Programs.” Santa Monica: RAND, 1994.

Schlenger, W. E. 1973. A Systems Approach to Drug User Services. Behavioral Science. 18, 137-147.

Sherman, L.W., D.C. Gottfredson, D.L. MacKenzie, J. Eck, P. Reuter, and S.D. Bushway, Preventing Crime: What Works, What Doesn't, What's Promising. Washington, D.C.: National Institute of Justice, 1997.

Stecher, Brian M., Christina A. Andrews, Laurie L. McDonald, Sally C. Morton, Elizabeth A. McGlynn, Laura Petersen, M. Audrey Burnam, Charles Hayes, Jerome V. Vaccaro. 1995. "Implementation of Residential and Nonresidential Treatment for the Dually Diagnosed Homeless," Evaluation Review, V. 18, no. 6.

Sturm, Roland and Rosalie Liccardo Pacula. 2000. "State Mental Health Parity Laws: Cause or Consequence of Differnces in Use?" Health Affairs, Vol. 18, No. 5.

Sturm, Roland, W. Zhang, and M. Schoenbaum. 1999. How Expensive Are Unlimited Substance Abuse Benefits Under Managed Care? Journal of Behavioral Health Services Research Vol. 26, No. 2, pp. 203-210.

Substance Abuse and Mental Health Services Administration, Office of Applied Studies (SAMHSA) Emergency Department Trends from the Drug Abuse Warning Network, Preliminary Estimates January - June 2001 with Revised Estimates 1994 - 2000. Washington, D.C.: U.S. Department of Health and Human Services, 2002a.

Substance Abuse and Mental Health Services Administration, Office of Applied Studies (SAMHSA) Mortality Data from the Drug Abuse Warning Network, 2000. DAWN Series D-19, DHHS Publication No. (SMA) 02-3633, Rockville, MD, 2002b.

Tobler, N.S. "Meta-Analysis of Adolescent Drug Prevention Programs: Results of the 1993 Meta-Analysis. Meta-Analysis of Drug Abuse Prevention Programs." ed. William J. Bukoski , NIDA Research Monograph 170, Washington, D.C.: U.S. Department of Health and Human Services, 1997:5-68.

Tragler, Gernot, Jonathan P. Caulkins, and Gustav Feichtinger. 2001. “Optimal Dynamic Allocation of Treatment and Enforcement in Illicit Drug Control." Operations Research, Vol. 49 No. 3, pp.352-362.

Turner, Barbara J., John A. Fleishman, Neil Wenger, Andrew S. London, M. Audrey Burnam, Martin F. Shapiro, Eric G. Bing, Michael D. Stein, Douglas Longshore, Samuel A. Bozzette. 2001. "Effects of Drug Abuse and Mental Disorders on Use and Type of Antiretroviral Therapy in HIV-Infected Persons" Journal of general internal medicine, v. 16 , no. 9 , Sept. 2001 , p. 625-633

Weatherburn, Don and Bronwyn Lind. 1997. On the Epidemiology of Offender Populations. Australian Journal of Psychology, Vol. 49, No. 3, pp.169-175.

Weatherburn, Don, Craig Jones, Karen Freeman, and Toni Makkai. 2001. The Australian Heroin Drought and Its Implications for Drug Policy. New South Wales Bureau of Crime Statistics and Research Publication B59, Sydney.

Woodward, A., J. Epstein, J., Gfroerer, D. Melnick, R. Thoreson, and D. Wilson. 1997. "The Drug Abuse Treatment Gap: Recent Estimates," Health Care Financing Review, Vol. 18, pp.5-17. 